\title{
Investigations on the Effect of Radius Rotor in Combined Darrieus-Savonius Wind Turbine
}

\author{
Kaprawi Sahim $\mathbb{D}$, Dyos Santoso, and Dewi Puspitasari \\ Mechanical Engineering Department, Sriwijaya University, Sumatera Selatan, Indonesia \\ Correspondence should be addressed to Kaprawi Sahim; kaprawis@yahoo.com
}

Received 23 October 2017; Accepted 10 January 2018; Published 1 March 2018

Academic Editor: Tariq Iqbal

Copyright (C) 2018 Kaprawi Sahim et al. This is an open access article distributed under the Creative Commons Attribution License, which permits unrestricted use, distribution, and reproduction in any medium, provided the original work is properly cited.

Renewable sources of energy, abundant in availability, are needed to be exploited with adaptable technology. For wind energy, the wind turbine is very well adapted to generate electricity. Among the different typologies, small scale Vertical Axis Wind Turbines (VAWT) present the greatest potential for off-grid power generation at low wind speeds. The combined Darrieus-Savonius wind turbine is intended to enhance the performance of the Darrieus rotor in low speed. In combined turbine, the Savonius buckets are always attached at the rotor shaft and the Darrieus blades are installed far from the shaft which have arm attaching to the shaft. A simple combined turbine offers two rotors on the same shaft. The combined turbine that consists of two Darrieus and Savonius blades was tested in wind tunnel test section with constant wind velocity and its performance was assessed in terms of power and torque coefficients. The study gives the effect of the radius ratio between Savonius and Darrieus rotor on the performance of the turbine. The results show that there is a significant influence on the turbine performance if the radius ratio was changed.

\section{Introduction}

Darrieus and Savonius wind turbines are the most common VAWTs. The Savonius wind turbine is an aerodynamically drag based, self-starting turbine with low cut in speed, but its inefficiency curtails it to fewer applications, whereas Darrieus wind turbines are aerodynamically lifting based turbines having higher cut in speed with higher coefficients of performance. Thus, it can rotate faster than the wind velocity. Combined rotors are the combination of Darrieus and Savonius rotors mounted on the same shaft. Mostly combined wind turbines are available in the vertical axis configuration. Figure 1 gives a performance comparison of the various types of all conventional turbines that have been constructed [1]. As can be seen in the figure, turbines with horizontal axis have high power coefficient among other turbines which reach $49 \%$ in $\lambda \approx 7$. All turbines with vertical shaft have low power coefficient and the smallest power coefficient is Savonius turbine having maximum power coefficient 0.15 on $\lambda \approx 0.8$.

1.1. Darrieus Turbine. Various types of Darrieus turbine rotor configuration exist; among them are: egg beater type, straight blade type, and helical blade rotor. To increase the Darrieus turbine performance, Takao et al. [2] placed a guide vane row upstream of the rotor in order to enhance its torque, so the power coefficient of the turbine is 1.5 times higher than that of the original turbine which has no guide vane. The micro Darrieus turbine consists of usually two or three pairs of airfoils of NACA type and each pair has a single blade. Configuration of each pair consists of two blades, where one of them is auxiliary blade and gives a higher static torque [3]. The number of Darrieus blades influences the turbine performance. The fewer the number of blades, the higher the performance of the rotor [4]. The use of double blades of solo Darrieus rotor makes the turbine lower in performance [5].

The effect of an upstream flat deflector on the power output of two counterrotating straight-bladed Darrieus wind turbines was investigated experimentally $[6,7]$. The result shows that the power output of a turbine increases significantly. The effect of solidity will increase the torque of $\mathrm{H}$ Darrieus turbine, but increasing solidity alone does not improve the performance of the rotor since there is an effect of blockage and interaction [8]. The new model of Darrieus blade is introduced by Zamani et al. [9] in using J-shaped profile; the wind turbine performance and self-starting of 


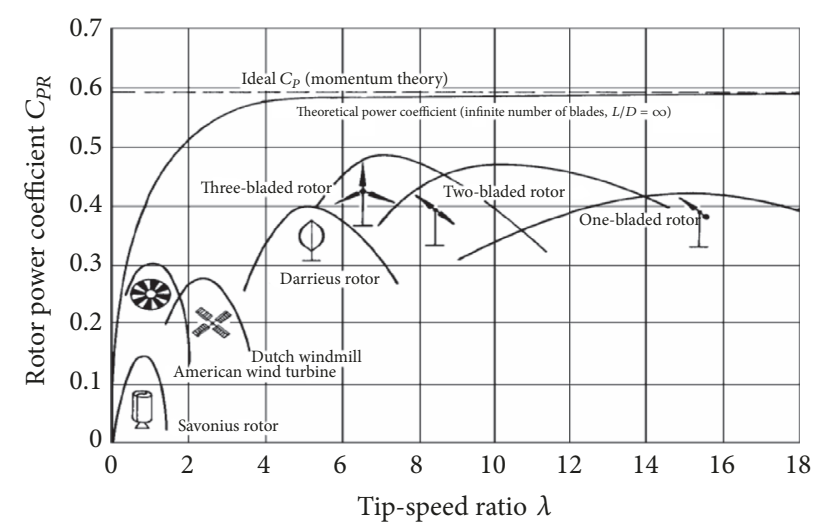

FIGURE 1: Typical performance of wind power machines.

turbine are improved. It has been experimented that, by the combination of both Darrieus and Savonius rotor, higher coefficient of performance could be achieved at moderate wind speed.

1.2. Savonius Turbine. A vertical axis wind turbine (VAWT) is summarized as accepting wind from any direction and self-starting at low cut in speeds. Two semicircle blades were usually chosen for the Savonius rotor because of their excellent start-up performance. The double-step Savonius bucket was proposed since the starting torque is never negative [10]. The combination of two geometries of the surface curve of Savonius bucket was studied by Sanusi et al. [11]. The concave side is a half-circle and the other side is in a semicircular form. They show experimentally that the combined blade improved the performance of Savonius turbine. Torque variation on the angular positions of the rotor blade and lower efficiency are the main drawbacks of Savonius turbine. To overcome the problem, Thiyagaraj et al. [12] placed a set of additional blades called secondary blades in front of the concave side of main rotor blades. Thus the efficiency is improved and the torque values increased along the angular positions. To increase the power coefficient of Savonius turbine, Al-Kayiem et al. [13] proposed installing a curtain in upstream flow of turbine and the rotor without shaft. By these configurations, the coefficient of power increase significantly.

A considerable improvement in the performance of Savonius rotor can be achieved by using multiple quarter blades instead of single blade as shown by S. Sharma and R. K. Sharma [14]. The twisted Savonius bucket was tested to know the optimum twisted angle of the blade. The optimum angle is found to be $15^{\circ}[15]$ and for blade arc angle the range is $110^{\circ}-135^{\circ}$ [16]. The performance of the newly developed two-blade Savonius wind turbine is reported by Roy and Saha [17] by modifying the blade called Bach, Benesh, and semielliptical blades. New model of Savonius blade having arm is given by Roy and Ducoin [18]. The performance is better than the conventional turbine. The use of ventilation in the Savonius blade improved the performance of the conventional Savonius windmill. This improvement in power coefficient achieves $25 \%$ of low wind speed [19]. The power coefficient can be increased by placing two deflectors upstream of rotor [20].

The performance and shape characteristics of a helical Savonius wind turbine at various helical angles have an influence on the turbine performance [21]. Type of the blade fullness of Savonius was introduced by Tian et al. [22] which gives the optimum performance of Savonius wind turbine. The aspect ratio defined as height to diameter of Savonius rotor influences torque of the rotor. The torque of a rotor can be increased by decreasing aspect ratio, and the speed can be increased by increasing aspect ratio [23].

1.3. Combined Darrieus and Savonius Turbine. The DarrieusSavonius rotor combines the advantage of Savonius rotor, that is, high starting torque, and the advantage of Darrieus rotor, that is, a high power coefficient, into a single combination of these rotors. A combined Savonius-Darrieus type vertical axis wind rotor has many advantages over individual Savonius or individual Darrieus wind rotor, such as better efficiency than the Savonius rotor and high starting torque than the Darrieus rotor. However to make the rotor completely self-starting, the rotor is incorporated into a hybrid system with Savonius rotor as its starter. It was found that the hybrid design fully exhibits the self-starting capability at all azimuthal positions, signified by the positive static torque coefficient values, and the power performance of the hybrid rotor increases to 0.34 [24].

There are some possible combined configurations of turbines. Savonius is placed in the middle of the Darrieus rotor, Darrieus rotor is placed above the Savonius rotor, and Savonius was placed at the top of Darrieus rotor. The first configuration gives the highest coefficient of power [25]. The efficiency of Darrieus and Savonius turbine depends on upstream fluid velocity. The higher the velocity, the higher the efficiency of the turbine [26].

The overlap between Savonius blades of combined Darrieus-Savonius rotor increases the performance of the combined turbine [27]. Combined Darrieus-Savonius turbine is tested in water current flow by using a flat deflector upstream of the turbine. The deflector increases the performance of the combined turbine [28]. A combined three-bladed Darrieus and three-bucket Savonius rotor is explored by Ghosh et al. [29]. They show that the power coefficient is obtained at 0.53 for Darrieus rotor mounted on the Savonius rotor which is better than rotor in which Savonius is mounted on Darrieus rotor. The optimum value of attachment angle of Savonius buckets to the Darrieus rotor is perpendicular to the Darrieus blade arm because at this condition it gives greater torque at low speed as shown experimentally by Kyozuka [30]. For the different angle of attachment, the performances have small differences. Xiaoting et al. [31] compute the optimum angle of attachment. The optimum angle of attachment of Savonius rotor is $0^{\circ}$ and they also show that the radius ratio, $\mathrm{KD}$, between Savonius and Darrieus radius is better if $\mathrm{KD}<0.5$.

From the literature surveys described above, for a combined Darrieus and Savonius wind turbine, the dimensionless radius ratio between Savonius and Darrieus rotor is not yet studied experimentally. It seems that the gap distance between Savonius and Darrieus blades is an important 


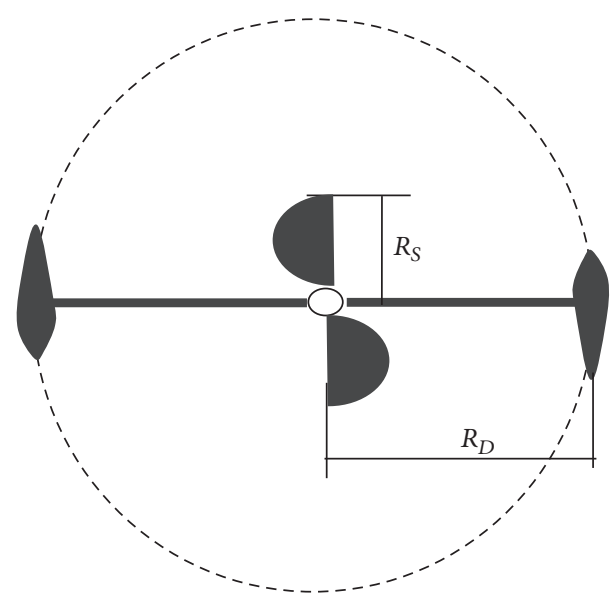

FIgURE 2: Combined Darrieus and Savonius turbine.

parameter which can influence the combined turbine performance. It is the reason that the objective of the present study is to explore experimentally the performance of a combined Darrieus and Savonius wind turbine.

\section{Experimental Study}

The combined wind turbine was tested in a subsonic wind tunnel laboratory with test cross section of $400 \times 400 \mathrm{~mm}^{2}$. The design should fit in the cross section; thus a micro combined Darrieus and Savonius wind turbine is designed and fabricated.

2.1. Model Test. The schematic figure of the combined rotor is shown by Figure 2 where the Savonius rotor is placed perpendicular to the Darrieus rotor. In the present investigations, two main configurations in the study were investigated since there are two ways to make the variation of dimensionless radius ratios as follows.

(a) Radius of Savonius bucket $R_{S}$ is kept fixed and radius of Darrieus rotor $R_{D}$ is varied (case (a)).

(b) Radius of Darrieus rotor is kept fixed, the radius of Savonius is varied. It means that the diameter of semicircular Savonius bucket became larger (case (b)).

The combined rotor has two Darrieus blades and two Savonius buckets (two semicircle buckets). The Savonius rotor is installed in the middle of the Darrieus rotor with the same shaft. The Darrieus airfoil is a NACA 0020 with chord length $60 \mathrm{~mm}$ and span length $300 \mathrm{~mm}$. The blade was made from wood and Darrieus rotor has $340 \mathrm{~mm}$ in diameter. The semicircular Savonius buckets have the same length as the Darrieus blade and were made from polyvinyl chloride (PVC) material. The radius ratio is written as $\mathrm{RL}=R_{S} / R_{D}$, where $R_{S}$ is radius of Savonius rotor and $R_{D}$ is radius of Darrieus rotor. The above Darrieus blade dimensions give the solidity of rotor as $\sigma=0.11$.

2.2. Procedures. The combined rotor was installed in wind tunnel section with wind velocity set at $8 \mathrm{~m} / \mathrm{s}$ which is

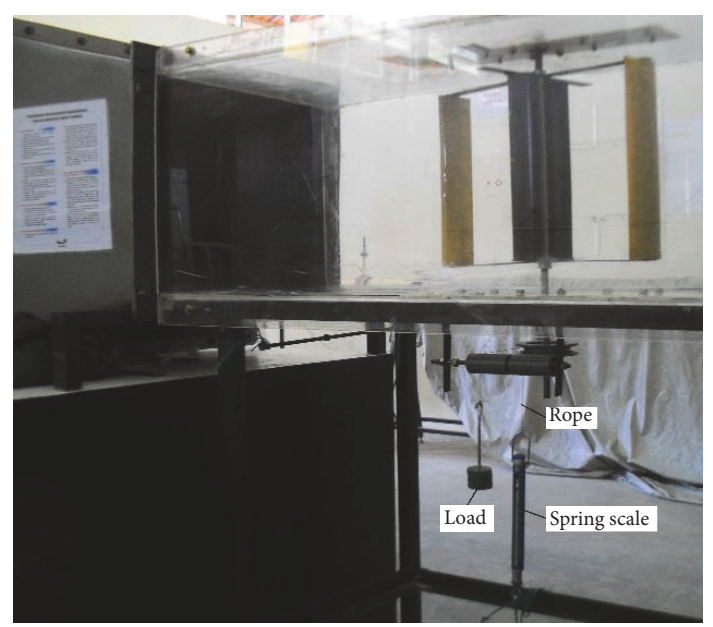

FIGURE 3: Photograph of turbine in wind tunnel.

constant along the test. The photograph of turbine in the wind tunnel is shown in Figure 3. Two ball bearings were used in the base to support the shaft. The shaft was made up of mild-steel of $12 \mathrm{~mm}$ diameters. The structure of Darrieus arm was made of strip of cast iron to ensure high strength to weight ratio and durability. Flexible digital anemometer and digital laser tachometer were used to measure the wind speed and revolutions per minute of the rotor. Torque meter which is installed on rotor shaft of a wind turbine can determine power and torque coefficients absorbed from a wind turbine. Type of rope brake dynamometer meter was used to measure torque. Torque meter consists of a rope, a brake pulley, a tube spring scale, and a pan. The weighing pan, brake pulley, and tube spring scale are connected by a nylon string of $2 \mathrm{~mm}$ in diameter.

The first step of measurements was carried out without load. Then, while the rotor was running, a load was added; then force on tube spring scale and rotation was measured. The same measurements were done for the other loads. At certain load, the rotor was stopped since the load was maximized.

The performance of a wind turbine can be expressed in the form of torque coefficient $\left(C_{T}\right)$ and the coefficient of power $\left(C_{P}\right)$. Tip speed ratio or $\operatorname{TSR}(\lambda)$ is a parameter related to rated wind speed and rotor diameter. $\lambda$ is the ratio between speed of tip blade and wind speed through the blade; TSR is determined as follows.

$$
\lambda=\frac{U}{V}=\frac{\omega \cdot r}{V}
$$

where $U$ is the tip speed or the peripheral velocity of the rotor, in the case of combined turbine the speed of Darrieus rotor, $V$ is the wind speed, $\omega$ is the angular velocity of the rotor, and $r$ is the radius of the rotor.

The coefficient of torque or $C_{T}$ is defined as the ratio between the actual torque developed by the rotor $(T)$ and 
the theoretical torque available in the wind as expressed by

$$
\begin{aligned}
C_{T} & =\frac{T}{T_{W}}=\frac{4 \cdot T}{\rho \cdot A \cdot d \cdot V^{2}} \\
\text { or } C_{T} & =\frac{C_{P}}{\lambda},
\end{aligned}
$$

where $\rho$ is the density of air, $T$ is the torque, and $A$ is the swept area of blades $=$ the rotor height $\times$ the rotor diameter. The force acting on the rotor shaft is obtained in $(\mathrm{N})$ by

$$
F=(s-m) g,
$$

where $s$ is the spring balance reading in $\mathrm{kg}, m$ is the mass loaded on the pan in $\mathrm{kg}$, and $g$ is the gravitational acceleration. The torque is calculated from the following relation.

$$
T=\left(r_{b}+r_{r}\right) \cdot F,
$$

where the $r_{b}$ is radius of brake drum and the $r_{r}$ is radius of the rope.

The coefficient of power of a wind turbine $\left(C_{P}\right)$ is the ratio between the maximum power obtained from the wind $\left(P_{T}\right)$ and the total power available from the wind $\left(P_{a}\right)$ :

$$
C_{P}=\frac{P_{T}}{P_{a}}=\frac{P_{T}}{(1 / 2) \rho A V^{3}},
$$

where $P_{T}$ is the power of turbine that is given by

$$
P_{T}=T \cdot \omega .
$$

\section{Results and Discussion}

Initial experiments were carried out for solo Savonius and Darrieus separately and then the two turbines were combined together. In this study, two important parameters of turbine performance in terms of torque and power coefficient were presented and all parameters of turbine performance were calculated from (1) to (6).

Figure 4 shows the variation of the coefficient of torque with tip speed ratio. The coefficient attains its highest value of the tip speed ratio $\lambda=1.8$ for solo Darrieus rotor and it decreases very slowly with lower speed. These characteristics give it less self-starting capability, while the torque coefficient decreases to zero or no load condition as speed ratio is larger or at $\lambda=2.7$. The solo Savonius rotor has a higher coefficient for low speed compared to solo Darrieus rotor and the torque coefficient decreases rapidly with $\lambda$ in the narrow range of $\lambda<0.6$. We note that the solo Savonius has rotor speed not greater than the upstream wind speed. When these two rotors are combined, it seems that the torque coefficients of all RL values increase significantly for low speeds. The higher the $\mathrm{RL}$, the greater the torque coefficient. As stated by Xiaoting et al. [31] the larger the RL ratio, the more the inference of the flow field by the Savonius rotor to the Darrieus rotor.

The power coefficient characteristics of the turbine rotors are presented in Figure 5. The solo Darrieus turbine has the

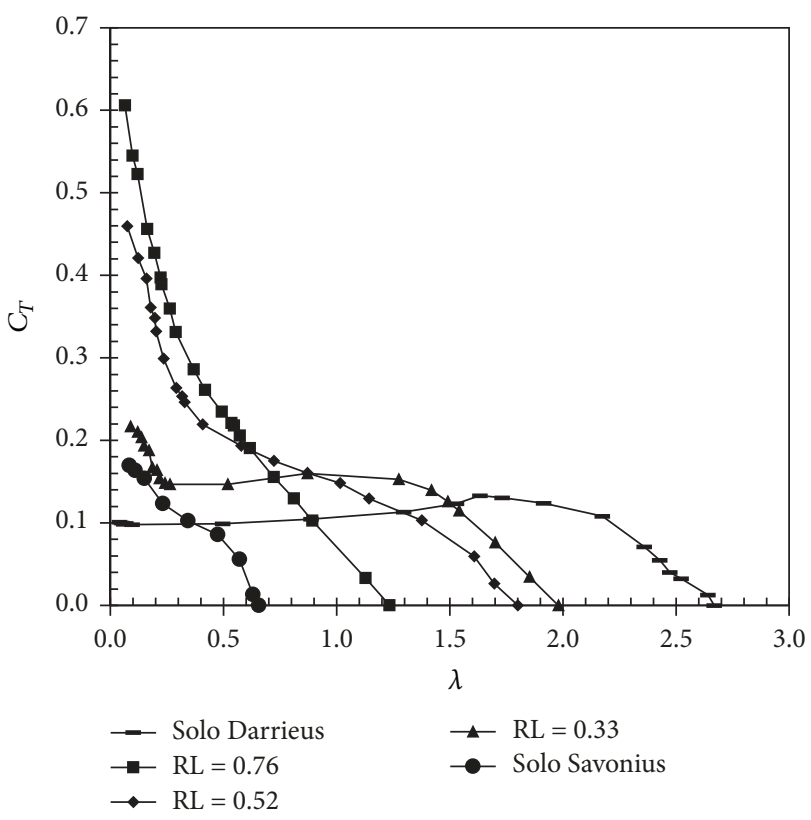

Figure 4: Coefficient of torque (case (a)).

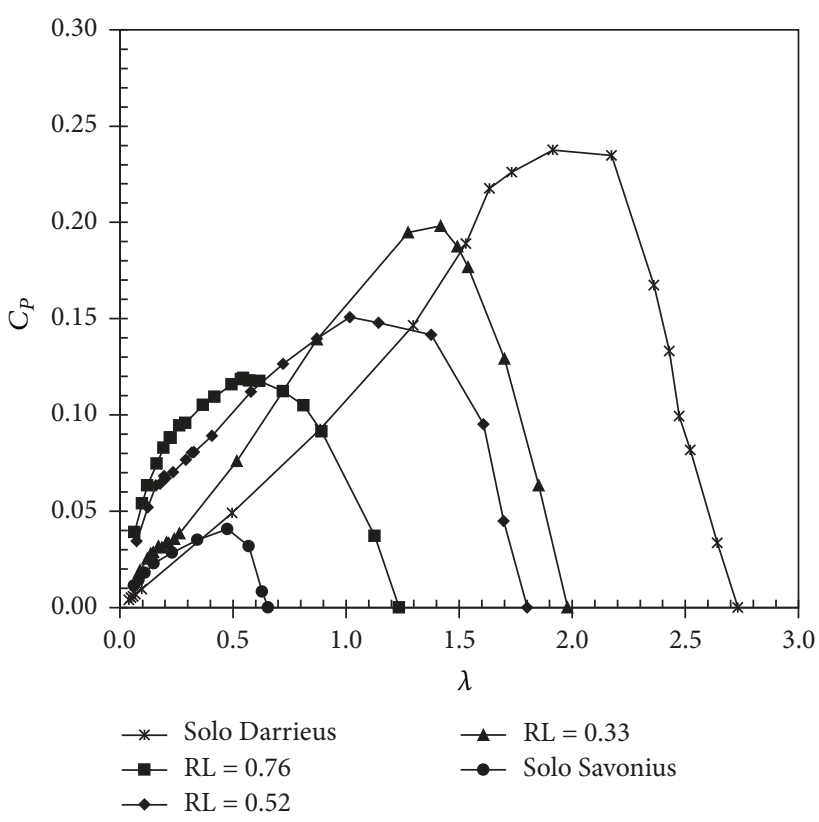

Figure 5: Coefficient of power (case (a)).

highest power coefficient that attains maximum values $C_{P}=$ 0.238 at about $\lambda=2$. The solo Darrieus turbine has also a wide range of operation speed from $\lambda=0$ to 2.7. It is much larger than that of Savonius turbine. It is observed that the lowest power coefficient is found in solo Savonius turbine that has a maximum value of $C_{P}=0.041$ at about $\lambda=0.5$. For the combined turbine in which the Darrieus blades are at the nearest from the Savonius rotor or $\mathrm{RL}=0.76$, the maximum power coefficient is found to be $C_{P}=0.12$. When RL decreases from $\mathrm{RL}=0.76$ to 0.33 , the value of $C_{P}$ increases considerably. The lower value of RL will improve the 


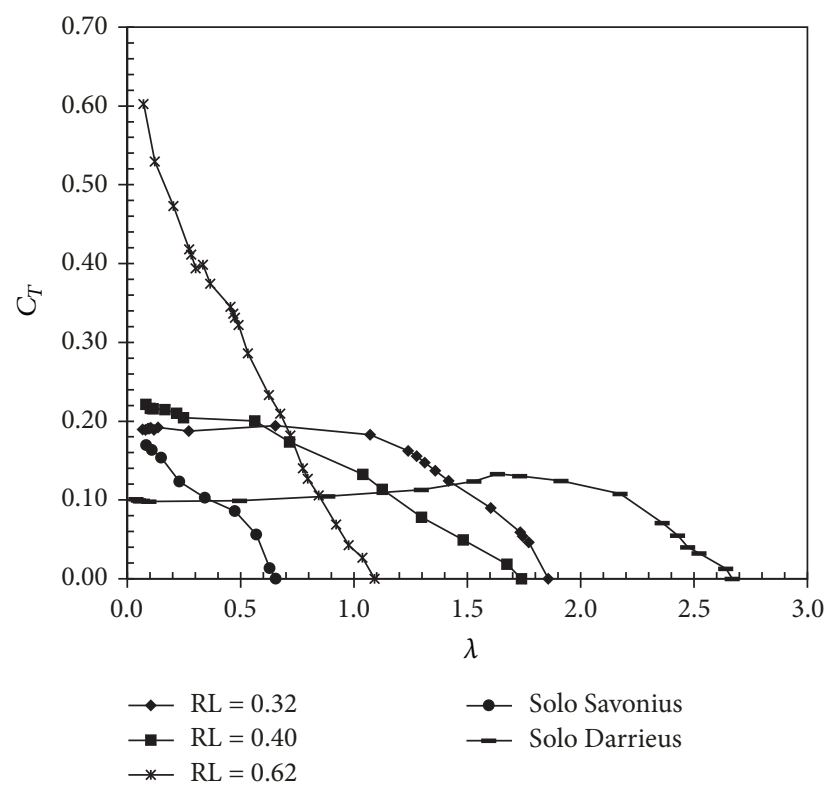

FIGURE 6: Torque coefficient variation (case (b)). power coefficient of combined turbine since the maximum power coefficient increases and the curves shifted to the right which makes the operation speed become larger. The higher speed of the combined turbine is due to the Darrieus being far from Savonius and no interference occurs. As we noted the dimensionless parameter RL represents the ratio between the frontal area of Savonius rotor and the frontal area of the Darrieus rotor since both rotors have the same height. In this study, the Savonius rotor has ratio $H / D=2.7$, where $H$ is the height of the rotor and $D$ is the rotor diameter. The power coefficient of a turbine is influenced by the amount of energy loss due mechanical structure. In this case, a friction exists between wind and blades, and mechanical friction exists in the bearing. However, the friction in the system is difficult to quantify.

In the case of the radius of Darrieus rotor being kept fixed and the radius of Savonius bucket being varied, the torque coefficient of combined rotor is shown in Figure 6. It is observed that, at low speed, the torque increases in the increase in RL. The torque variation is considerably large for $\mathrm{RL}=0.62$; it decreases rapidly with $\lambda$, while for the other two $\mathrm{RL}$ the torque variation is not so large. $\mathrm{RL}=0.62$ means that the Savonius bucket is larger and/or it absorbed much energy from wind to rotate the rotor. Smaller blades will absorb less wind energy due to the decrease of frontal area. As the diameter of Savonius was increased, the inertia of the rotor increased thereby reducing its speed. For $\mathrm{RL}=0.32$ and 0.40 , the two curves seem to be similar except at very low speed since these two values of RL are not much different. However, it can be concluded that the variations in RL are sensitive to the torque variations and the higher the RL, the higher the torque coefficient, but the speed reduced.

The variations in RL value show also the variation in an aspect ratio of the Savonius rotor $(\mathrm{AR}=H / D)$ in combined rotor. A low value of RL indicates high AR. The power

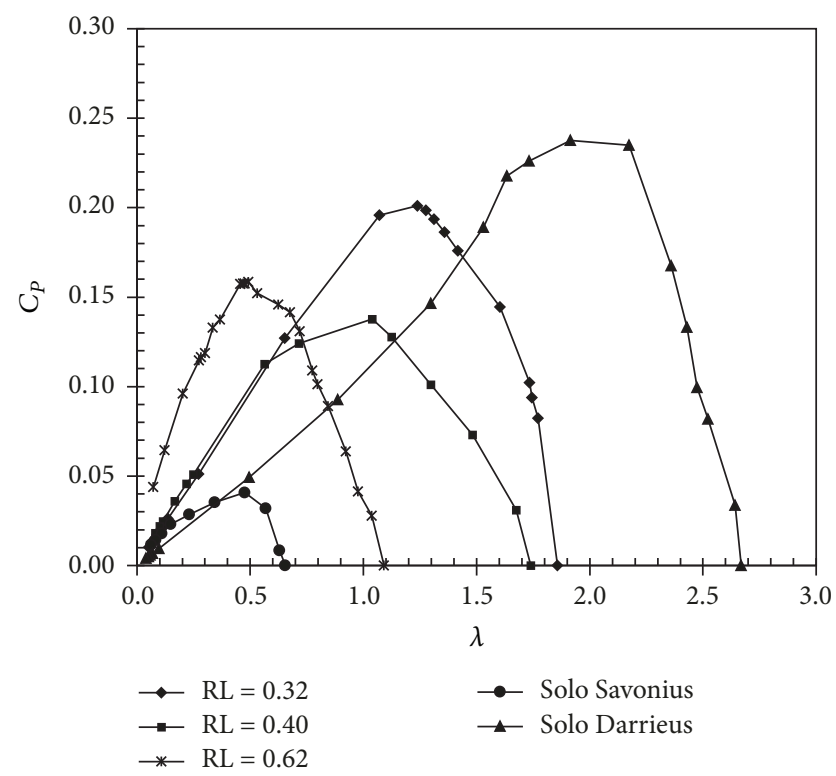

Figure 7: Coefficient of power (case (b)).

coefficient of combined rotor for case (b) is shown in Figure 7. As seen in the figure, the maximum power coefficients have been obtained around 0.198 for $\mathrm{RL}=0.32,0.138$ for $\mathrm{RL}=$ 0.40 , and 0.158 for $R L=0.62$. The curves show that the higher power coefficient is found for low RL, but when RL increases, the power coefficient decreases. For low speed, the power coefficient of rotor with $\mathrm{RL}=0.62$ is higher than that of the rotor with $\mathrm{RL}=0.40$ since the torque profile is much higher at lower speed for $\mathrm{RL}=0.62$. It is concluded that the higher the dimension of Savonius bucket is, the higher the losses become; thereby the performance decreases.

The torque coefficient for all configurations (cases (a) and (b)) of the combined turbine has higher values than that of solo Darrieus and solo Savonius for low speed. The maximum ranges of power coefficient of all configurations and all RL are similar, which vary from the range of 0.12 to 0.20 (Figures 5 and 7), but the speed ranges are higher for first configuration (case (a)). It is observed further that, for the low value of $\lambda$ and for $\mathrm{RL}=0.52$ (Figure 4 ), the torque coefficient is quite high compared to that of $\mathrm{RL}=0.33$ but it is lower than that for $R L=0.76$. The operational speed range of $R L=0.76$ is lower compared to the two other values of RL. The other part (Figure 5), the maximum power coefficient for $\mathrm{RL}=0.52$, is not too low. So it seems that the optimum condition occurs to $\mathrm{RL}=0.52$. For the better condition in the design of a combined wind turbine, the rotor should have a self-starting point at low speed, a high torque operation, a high speed, and a high power coefficient. So it is suggested to use the radius ratio $0.30 \leq \mathrm{RL} \leq 0.50$ in the design of a combined turbine. For very low RL can produce a negative torque [31]

\section{Conclusions}

In this study, an experimental study in a wind tunnel has been carried out in order to explore the influence of rotor radius of combined Darrieus-Savonius turbine on performance. The 
dimensionless radius is called RL, which is the ratio of the Savonius rotor to the Darrieus rotor. The results conclude that the variation in Darrieus rotor radius in a combined turbine has an important effect on the turbine performance. The higher the RL, the lower the power coefficient and the higher the torque coefficient. Similarly, in case of increasing the Savonius rotor radius, the power coefficient is lower but torque coefficient is higher.

The combined Darrieus-Savonius wind turbine is simple in construction, low cost, and self-starting at low wind speed. This makes it suitable for generating electrical energy, such as for household application at rural areas and for a sailboat.

\section{Conflicts of Interest}

The authors declare that there are no conflicts of interest regarding the publication of this paper.

\section{Acknowledgments}

The authors acknowledge Sriwijaya University for the research grant of scheme Unggulan Profesi.

\section{References}

[1] R. E. Wilson and P. B. S. Lissaman, "Applied aerodynamics of wind machines," Research Applied to National Needs, vol. GI41840, 1974.

[2] M. Takao, T. Maeda, Y. Kamada, M. Oki, and H. Kuma, "A straight-bladed vertical axis wind turbine with a directed guide vane row," Journal of Fluid Science and Technology, vol. 3, no. 3, pp. 379-386, 2008.

[3] M. Scungio, F. Arpino, V. Focanti, M. Profili, and M. Rotondi, "Wind tunnel testing of scaled models of a newly developed Darrieus-style vertical axis wind turbine with auxiliary straight blades," Energy Conversion and Management, vol. 130, pp. 6070, 2016.

[4] Q. Li, T. Maeda, Y. Kamada, J. Murata, K. Furukawa, and M. Yamamoto, "Effect of number of blades on aerodynamic forces on a straight-bladed Vertical Axis Wind Turbine," Energy, vol. 90, pp. 784-795, 2015.

[5] Y. Hara, T. Kawamura, H. Akimoto, K. Tanaka, T. Nakamura, and K. Mizumukai, "Predicting double-blade vertical axis wind turbine performance by a quadruple-multiple streamtube model," The International Journal of Fluid Machinery and Systems, vol. 7, no. 1, pp. 16-27, 2014.

[6] D. Kim and M. Gharib, "Efficiency improvement of straightbladed vertical-axis wind turbines with an upstream deflector," Journal of Wind Engineering \& Industrial Aerodynamics, vol. 115, pp. 48-52, 2013.

[7] C. Stout, S. Arnott, S. Islam et al., "Efficiency improvement of vertical axis wind turbines with an upstream deflector efficiency improvement of vertical axis wind turbines with an upstream deflector," Energy Procedia, vol. 118, p. 9, 2017.

[8] S. Joo, H. Choi, and J. Lee, "Aerodynamic characteristics of twobladed H-Darrieus at various solidities and rotating speeds," Energy, vol. 90, part 1, pp. 439-451, 2015.

[9] M. Zamani, S. Nazari, S. A. Moshizi, and M. J. Maghrebi, “Three dimensional simulation of J-shaped Darrieus vertical axis wind turbine," Energy, vol. 116, pp. 1243-1255, 2016.
[10] J.-L. Menet, "A double-step Savonius rotor for local production of electricity: A design study," Journal of Renewable Energy, vol. 29, no. 11, pp. 1843-1862, 2004.

[11] A. Sanusi, S. Soeparman, S. Wahyudi, and L. Yuliati, "Experimental study of combined blade savonius wind turbine," International Journal of Renewable Energy Research, vol. 6, no. 2, pp. 615-619, 2016.

[12] J. Thiyagaraj, I. Rahamathullah, and P. S. Prabu, "Experimental investigations on the performance characteristics of a modified four bladed Savonius hydro-kinetic turbine," International Journal of Renewable Energy Research, vol. 6, no. 4, pp. 1530-1536, 2016.

[13] H. H. Al-Kayiem, B. A. Bhayo, and M. Assadi, "Comparative critique on the design parameters and their effect on the performance of S-rotors," Journal of Renewable Energy, vol. 99, pp. 1306-1317, 2016.

[14] S. Sharma and R. K. Sharma, "Performance improvement of Savonius rotor using multiple quarter blades - A CFD investigation," Energy Conversion and Management, vol. 127, pp. 43-54, 2016.

[15] U. K. Saha and M. J. Rajkumar, "On the performance analysis of Savonius rotor with twisted blades," Journal of Renewable Energy, vol. 31, no. 11, pp. 1776-1788, 2006.

[16] A. Kumar and R. P. Saini, "Performance analysis of a single stage modified Savonius hydrokinetic turbine having twisted blades," Journal of Renewable Energy, vol. 113, pp. 461-478, 2017.

[17] S. Roy and U. K. Saha, "Wind tunnel experiments of a newly developed two-bladed Savonius-style wind turbine," Applied Energy, vol. 137, pp. 117-125, 2015.

[18] S. Roy and A. Ducoin, "Unsteady analysis on the instantaneous forces and moment arms acting on a novel Savonius-style wind turbine," Energy Conversion and Management, vol. 121, pp. 281296, 2016.

[19] R. Hariyanto, S. Soeparman, W. Denny, and N. S. Mega, "Experimental study on improvement the performance of savonius windmill with ventilated blade," International Journal of Renewable Energy Research, vol. 6, no. 4, pp. 1403-1407, 2016.

[20] G. Kailash, T. I. Eldho, and S. V. Prabhu, "Performance study of modified savonius water turbine with two deflector plates," International Journal of Rotating Machinery, vol. 2012, Article ID 679247, 12 pages, 2012.

[21] J.-H. Lee, Y.-T. Lee, and H.-C. Lim, "Effect of twist angle on the performance of Savonius wind turbine," Journal of Renewable Energy, vol. 89, pp. 231-244, 2016.

[22] W. Tian, B. Song, J. H. Van Zwieten, and P. Pyakurel, “Computational fluid dynamics prediction of a modified savonius wind turbine with novel blade shapes," Energies, vol. 8, no. 8, pp. 79157929, 2015.

[23] W. Vance, "Vertical Axis Wind Rotors - Status and Potential," in Advanced Concepts Division Science Applications, Inc. La Jolla, California, Calif, USA, 1973.

[24] S. Bhuyan and A. Biswas, "Investigations on self-starting and performance characteristics of simple $\mathrm{H}$ and hybrid $\mathrm{H}$-Savonius vertical axis wind rotors," Energy Conversion and Management, vol. 87, pp. 859-867, 2014.

[25] A. Siddiqui, A. Hameed, S. N. Mian, and R. Khatoon, "Experimental Investigations of Hybrid Vertical Axis Wind Turbine," in Proceeding of the 4th International Conference on Energy, Environment and Sustainable Development (EESD '16), 2016.

[26] N. H. Mahmoud, A. A. El-Haroun, E. Wahba, and M. H. Nasef, "An experimental study on improvement of Savonius rotor 
performance," Alexandria Engineering Journal, vol. 51, no. 1, pp. 19-25, 2012.

[27] R. Gupta, A. Biswas, and K. K. Sharma, "Comparative study of a three-bucket Savonius rotor with a combined three-bucket Savonius-three-bladed Darrieus rotor," Journal of Renewable Energy, vol. 33, no. 9, pp. 1974-1981, 2008.

[28] S. Kaprawi, D. Santoso, and R. Sipahutar, "Performance of combined water turbine darrieus-savonius with two stage savonius buckets and single deflector," International Journal of Renewable Energy Research, vol. 5, no. 1, pp. 217-221, 2015.

[29] A. Ghosh, A. Biswas, K. K. Sharma, and R. Gupta, "Computational analysis of flow physics of a combined three bladed Darrieus Savonius wind rotor," Journal of the Energy Institute, vol. 88, no. 4, pp. 425-437, 2015.

[30] Y. Kyozuka, "An experimental study on the darrieus-savonius turbine for the tidal current power generation," Journal of Fluid Science and Technology, vol. 3, no. 3, pp. 439-449, 2008.

[31] L. Xiaoting, F. Sauchung, O. Baoxing, W. Chili, Y. C. Christopher, and P. Kaihong, "A Computational Study of the Effects of the Radius Ratio and Attachment Angle on the Performance of a Darrieus-Savonius Combined Wind Turbine," Renewable Energy, vol. 113, pp. 329-334, 2017. 


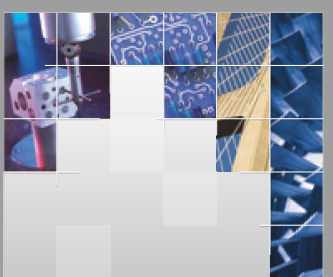

\section{Enfincering}
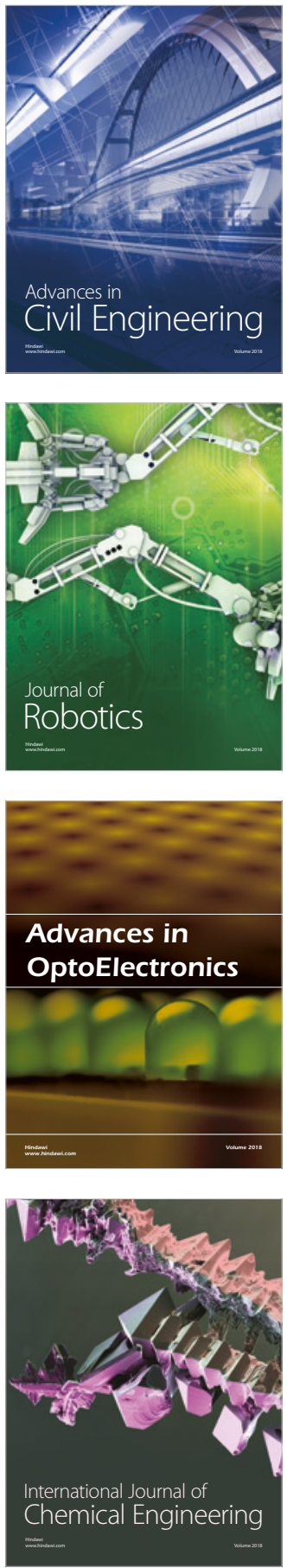

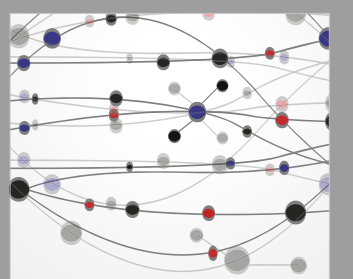

\section{Rotating \\ Machinery}

The Scientific World Journal

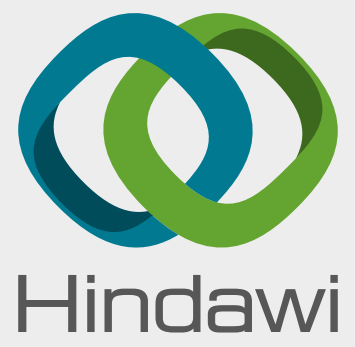

Submit your manuscripts at

www.hindawi.com
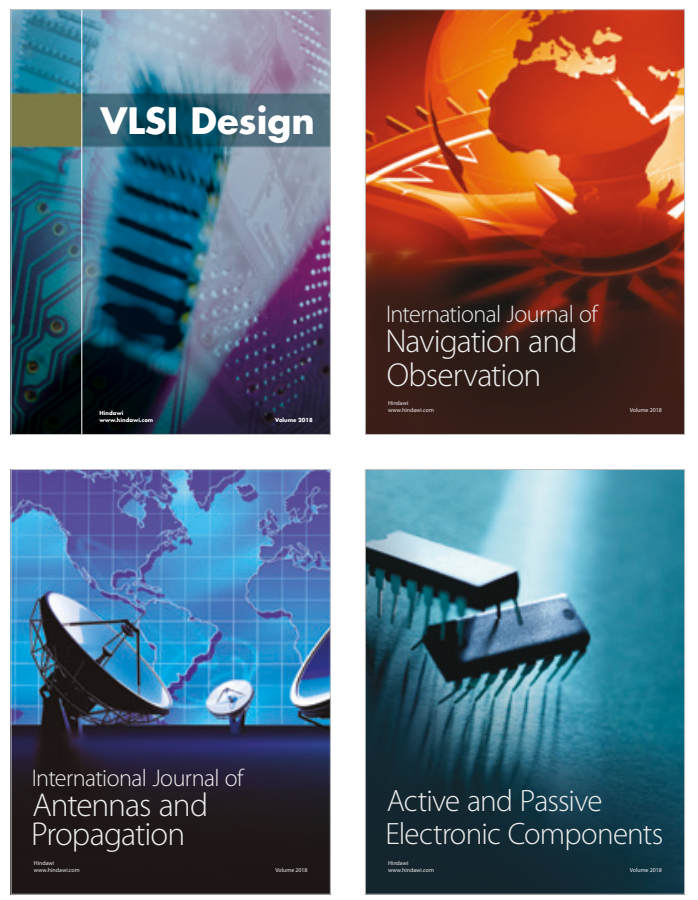
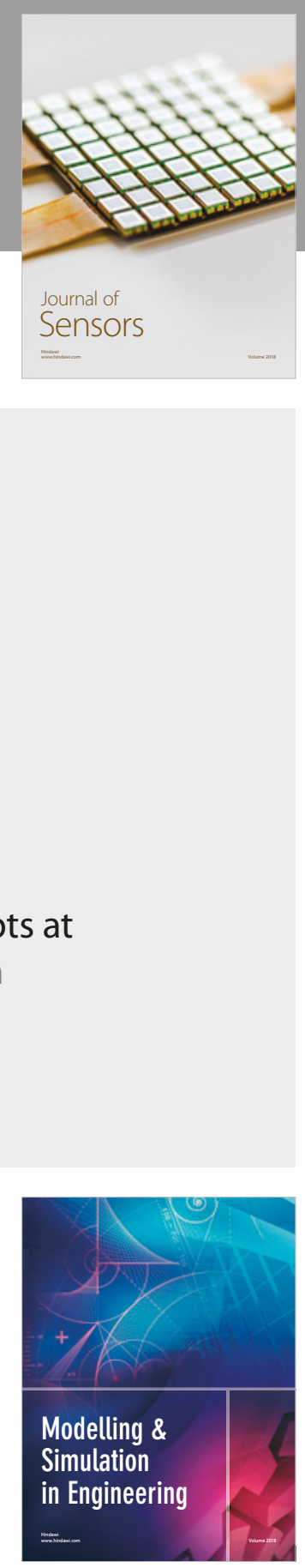

\section{Advances \\ Multimedia}
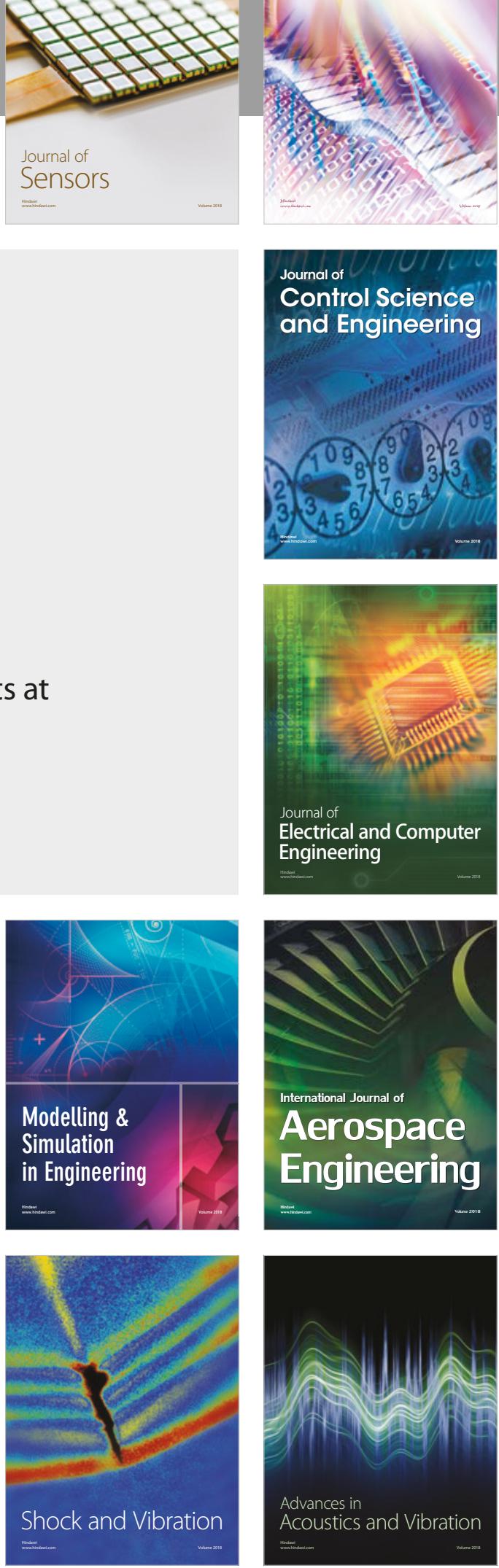